\title{
Identification of a Collagenase-Inhibiting Flavonoid from Alchemilla vulgaris Using NMR-Based Metabolomics*
}

\author{
Authors \\ Affiliations \\ 1 Institute of Biology, Leiden University, Leiden, The Nether- \\ lands \\ 2 Department of Pharmacy and Biotechnology, University of \\ Bologna, Bologna, Italy \\ 3 Department for Life Quality Studies, University of Bologna, \\ Rimini, Italy \\ 4 College of Pharmacy, Kyung Hee University, Seoul, Repub- \\ lic of Korea
}

Manuela Mandrone ${ }^{1,2}$, Aline Coqueiro ${ }^{1}$, Ferruccio Poli ${ }^{2}$, Fabiana Antognoni ${ }^{3}$, Young Hae Choi ${ }^{1,4}$

Key words

Alchemilla vulgaris, Rosaceae, flavonoids, quercetin-3-O- $\beta$ glucuronide, NMR-based metabolomics, collagenase inhibition

received February 16, 2018

revised May 2, 2018

accepted May 7, 2018

Bibliography

DOI https://doi.org/10.1055/a-0630-2079

Published online May 24, 2018 | Planta Med 2018; 84: 941946 ㄷ Georg Thieme Verlag KG Stuttgart · New York I ISSN 0032-0943

Correspondence

Dr. Manuela Mandrone

University of Bologna, Department of Pharmacy

and Biotechnology

Via Irnerio 42, 40126 Bologna, Italy

Phone: + 390512091294 , Fax: + 39051242576

manuela.mandrone2@unibo.it
Supporting information available online at

http://www.thieme-connect.de/products

\section{ABSTRACT}

This paper describes the use of ${ }^{1} \mathrm{H}$ NMR profiling and chemometrics in order to facilitate the selection of medicinal plants as potential sources of collagenase inhibitors. A total of 49 plants with reported ethnobotanical uses, such as the healing of wounds and burns, treatment of skin-related diseases, rheumatism, arthritis, and bone diseases, were initially chosen as potential candidates. The in vitro collagenase inhibitory activity of hydroalcoholic extracts of these plants was tested. Moreover, their phytochemical profiles were analyzed by ${ }^{1} \mathrm{H}$ NMR and combined with the inhibitory activity data by an orthogonal partial least squares model. The results showed a correlation between the bioactivity and the concentration of phenolics, including flavonoids, phenylpropanoids, and tannins, in the extracts. Considering the eventual false-positive effect on the bioactivity given by tannins, a tannin removal procedure was performed on the most active extracts. After this procedure, Alchemilla vulgaris was the most persistently active, proving to owe its activity to compounds other than tannins. Thus, this plant was selected as the most promising and further investigated through bioassay-guided fractionation, which resulted in the isolation of a flavonoid, quercetin3-O- $\beta$-glucuronide, as confirmed by NMR and HRMS spectra. This compound showed not only a higher activity than other flavonoids with the same aglycone moiety, but was also higher than doxycycline (positive control), the only Federal Drug Administration-approved collagenase inhibitor. The approach employed in this study, namely the integration of metabolomics and bioactivity-guided fractionation, showed great potential as a tool for plant selection and identification of bioactive compounds in natural product research.

\section{Introduction}

Plants and their metabolites are considered to be a very promising resource for the treatment of human diseases [1,2]. Nevertheless, plant-based drug discovery poses a number of challenges. In particular, the identification of the active principle(s) responsible for the bioactivity of a crude plant extract is particularly complicated due to the chemical complexity of the source matrix and the high dynamic range of metabolites [3].

The most commonly used workflow applied to date in the search for bioactive principles from natural sources has been a

* Dedicated to Professor Dr. Robert Verpoorte in recognition of his outstanding contribution to natural product research. 
bioactivity-guided fractionation approach. However, this procedure is time-consuming and cost-intensive and often requires a large amount of starting plant material. Moreover, in some cases, this approach has failed to explain the bioactivity of a crude extract [4], because the concentration of the bioactive compound is too low or, more often, because the activity is due to synergistic or additive effects, which are most likely lost during fractionation [5].

An emerging strategy to cope with these issues is based on the combination of chemometrics and metabolomics [6-9]. This approach relies on multivariate data analysis to correlate biological activity data and the phytochemical profiles of crude plant extracts and has been successfully used to guide and shorten the procedure for the identification of the active principles in crude extracts [10]. Moreover, it has also proved to be suitable for dereplication, which is the quick identification of already known active metabolites present in raw extracts. A dereplication strategy is particularly useful in the early stages of a plant-based drug discovery project, since it facilitates the selection of the most promising plants as sources of new active principles $[11,12]$.

The selection of the plants to be studied is a crucial step in natural product research. The use of a traditional medicine-based selection can increase the chances of discovering active principles and it also assumes that the components of these plant sources have higher chances to be safer than those that have not been used previously [13].

In the search for natural compounds endowed with in vitro anti-collagenase activity, 49 medicinal plants were chosen. Among them, 20 are used in the Ayurveda tradition in India, 18 in the traditional medicine of Central Africa, and 11 in the Mediterranean area. The selection of plants to be studied was based on reports of their traditional use as wound or burn healing enhancers, or to treat skin-related diseases in general (i.e., dermatitis, acne, urticaria, photoaging), rheumatism, arthritis, and bone diseases [14-18]. All these disorders have been associated with misregulated collagenase activity [19-21].

Collagenase is considered to be the founding member of the matrix metalloproteinases (MMPs) family, which are responsible for the degradation of extracellular matrix (ECM) constituents, such as collagen [22].

When searching for natural collagenase inhibitors, the first screening generally consists of submitting the potentially active plant extracts to an in vitro collagenase inhibitory assay [23-25]. In this study, the ${ }^{1} \mathrm{H}$ NMR spectrum of each extract was performed simultaneously and the data obtained were combined using multivariate data analysis (orthogonal partial least squares, OPLS) to correlate the ${ }^{1} \mathrm{H}$ NMR metabolomic profiles of the extracts to their respective percentage of collagenase inhibition. Through this procedure, it was possible to detect components of the extract that gave false-positive results in the in vitro test and gain more insight of the class of phytochemicals most possibly involved in the bioactivity.

This procedure allowed for the rapid identification of one of the forty-nine selected plants, Alchemilla vulgaris L. (Rosaceae) as the most promising source for natural collagenase inhibitors. This plant was then subjected to bioassay-guided fractionation to isolate and identify its active principle.

\section{Results and Discussion}

Forty-nine plants were screened with the purpose of identifying metabolites endowed with in vitro collagenase inhibitory activity. The selected plants were extracted in $\mathrm{MeOH} / \mathrm{H}_{2} \mathrm{O}(1: 1)$ and the extracts were tested at a fixed concentration of $50 \mu \mathrm{g} / \mathrm{mL}$, showing an inhibition percentage ranging from 0 to $100 \%$ (Table 1S, Supporting Information). The ${ }^{1} \mathrm{H}$ NMR metabolomic analysis of the extracts was carried out in order to obtain an overview of the relationship between the measured biological activity and the phytochemical profile of the extracts using OPLS, a supervised model. The model was built using ${ }^{1} \mathrm{H}$ NMR spectral data as $\mathrm{x}$ variables and the biological data as the $y$ variable. The correlation, however, was not validated $\left[Q^{2}=0.05\right.$ and $\left.p(C V-A N O V A)=0.22\right]$. A possible explanation for this lies in the large chemical variation among the tested medicinal plants. Initially, several scaling methods were applied to the data, e.g., Pareto, unit variance, and nonscaling, but none of the methods improved the validity of the model. Thus, as a next step, the raw data of the collagenase inhibition percentage was log-transformed. This greatly improved the validity $\left(Q^{2}=0.28\right.$ and $p$ value in $C$-ANOVA $\left.=0.002\right)$ as shown in

\section{- Fig. $1 \mathrm{~A}$.}

Due to the huge phytochemical variation among the samples, the biological activity was not expected to correlate to a specific metabolite. However, the most active plants showed a common pattern in their ${ }^{1} \mathrm{H}$ NMR spectra, indicating a high concentration of phenolic compounds. This general information was considered interesting since phenolic compounds are generally involved in enzyme inhibitory activities of plants and, in particular, in MMP inhibition $[26,27]$. The OPLS model revealed the correlation between the strength of collagenase inhibition and the signals in the aromatic region around $\delta 7.0$ in the ${ }^{1} \mathrm{H}$ NMR spectra. According to the S-plot obtained with this model ( $\vee$ Fig. 1 B), the most important signals that correlated with the strength of collagenase inhibition showed chemical shifts at $\delta 6.88$ and 7.08 , followed by other aromatic signals from $\delta 6.4$ to 6.9 . In the ${ }^{1} \mathrm{H}$ NMR spectra of the plant material, the presence of signals around $\delta 7.0$ can be attributed to tannin-related compounds, for instance, to their gallic acid moieties. This is consistent with some literature reports of the capacity of various tannins of inhibiting collagenase or other MMPs, both in in vitro and in vivo experiments [28, 29]. On the other hand, the well-known protein binding activity of tannins [30] could cause the precipitation of the enzymatic target when performing in vitro assays, leading to false positives, since the inhibition would occur following a nonspecific mechanism of action. These considerations, which emerged based on the OPLS model results, led to tannin removal from the 14 most active extracts (percentage of inhibition $>30 \%$ ) by column chromatography. The extracts were loaded on a polyamide column and eluted with $\mathrm{EtOH}$ to selectively retain the tannins on the resin (the yield after purification is displayed in - Fig. 2A). The collagenase inhibitory activity of the tannin-free extracts thus obtained proved to be much lower than that of the crude ones, with some exceptions. Among the 14 active plants, 3 of them, A. vulgaris L. (Rosaceae), Tinospora cordifolia Willd. (Menispermaceae), and Emblica officinalis Gaertn. (Primulaceae), retained a significant activity ( $\vee$ Fig. 2 B). The ${ }^{1} \mathrm{H}$ NMR spectra of the treated and untreated ex- 
A

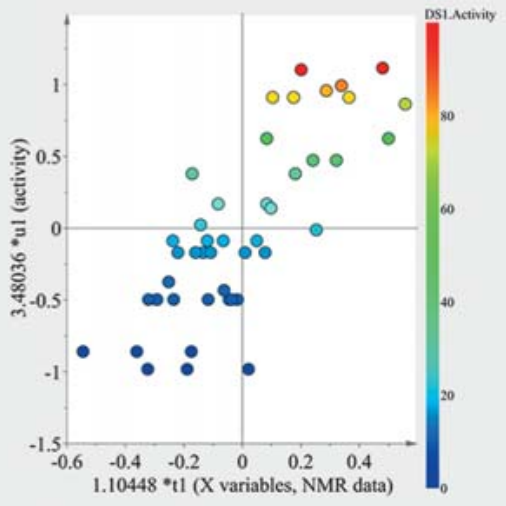

B

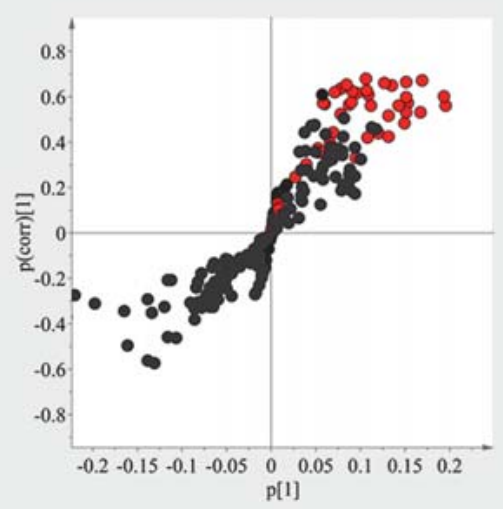

- Fig. 1 Orthogonal partial least square modeling using ${ }^{1} \mathrm{H}$ NMR data of 49 medicinal plants and collagenase inhibition. A Score plot of t1 (x variables of ${ }^{1} \mathrm{H}$ NMR data) versus $\mathrm{u} 1$ of the $y$ variable of the enzyme activity. B S-plot of variables. Red dots are the signals in the range of $\delta 6.4-7.7$. The signals highly correlated to the activity are in the range of $\delta 6.88$ to 7.08 .

A

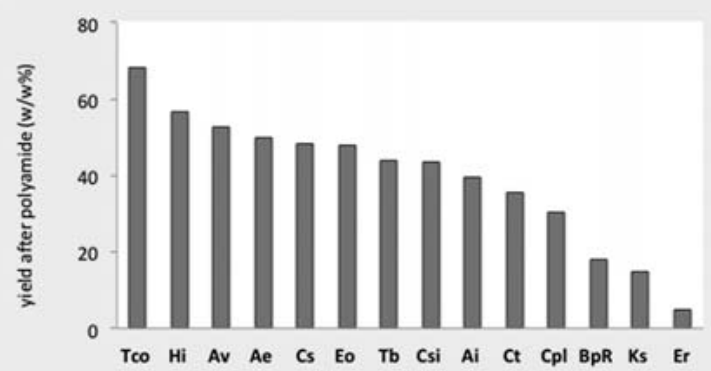

B

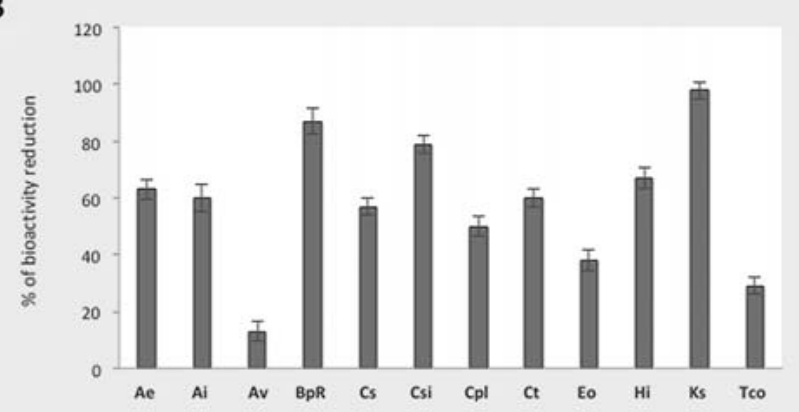

- Fig. 2 A Yield after polyamide purification (\%, w/w) of the most active plants. Ae=Agrimonia eupatoria, Ai = Azadirachta indica, Av= Alchemilla vulgaris, $\mathrm{BpR}=$ Vitellaria paradoxa (roots), $\mathrm{Cpl}=$ Cochlospermum planchonii, $\mathrm{Cs}=$ Camellia sinensis, $\mathrm{Csi}=$ Cassia sieberiana, $\mathrm{Ct}=\mathrm{Cochlospermum} \mathrm{tincto-}$ rium, Eo $=$ Emblica officinalis, $\mathrm{Er}=$ Embelia ribes, $\mathrm{Hi}=$ Hemidesmus indicus, $\mathrm{Ks}=$ Khaya senegalensis, $\mathrm{Tb}=$ Terminalia belerica, $\mathrm{Tco}=$ Tinospora cordifolia . B Decrease in collagenase inhibitory activity of the 14 most active plants after tannin removal. Tannin-free extract of Av almost retains the activity of the crude one. Values are expressed as the percentage of bioactivity reduction \pm SD.

tracts were compared, showing that in the case of Hemidesmus indicus L. (Apocynaceae), not only the tannins but also the vanillin positional isomer 2-hydroxy-4-methoxy-benzaldheyde was retained on the polyamide resin (Fig. 1S, Supporting Information). To evaluate the importance of this compound, a pure standard was tested, which showed no collagenase inhibitory activity even at the highest concentrations. Thus, it was concluded that the loss of activity by the $\mathrm{H}$. indicus tannin-free extract was related to tannins rather than to the absence of this metabolite.

The first stage of this study allowed the selection of $A$. vulgaris as the most interesting plant, since its activity was very slightly affected by the removal of tannins ( $\bullet$ Fig. $\mathbf{2 B}$ ). The overview provided by the OPLS model was of great importance, since it suggested proceeding with tannin removal; without this procedure, a plant with interfering compounds could have been selected as the most interesting, leading plant to isolate compounds with false-positive activity.
Thus, A. vulgaris was subjected to bioassay-guided fractionation in order to determine the compound responsible for its biological activity. The fractionation scheme consisted of an initial liquid-liquid partition of the crude extract with $n$-hexane, $\mathrm{CHCl}_{3}$, and $n-\mathrm{BuOH}$. The most active fraction $(n-\mathrm{BuOH})$ was further purified by column chromatography. Also, in this stage, the information given by the multivariate data treatment was relevant, allowing for the shortening of the bioassay-guided fractionation procedure. The first chromatographic step was performed on an HP-20 resin column to purify the extract from sugars and other primary metabolites, and obtain fractions enriched in the secondary metabolites. Since this first fractionation, the bioactivity of the obtained fractions was proportional to the intensity of typical flavonoid ${ }^{1} \mathrm{H}$ NMR spectral signals. On this basis and considering the results of the OPLS model, the compound responsible for these signals was targeted for isolation, speeding up the overall process. 
- Table 1 Collagenase activity inhibition by quercetin-3-O- $\beta$-glucuronide, quercitrin, rutin, and doxycycline.

\begin{tabular}{|l|c|c|}
\hline & $\mathbf{I C}_{\mathbf{5 0}}(\boldsymbol{\mu M})$ & $\mathbf{I C}_{\mathbf{5 0}} \mathbf{9 5 \%} \mathbf{C l}(\boldsymbol{\mu M})$ \\
\hline Doxycycline & 253.52 & $251.24-255.81$ \\
\hline Quercitrin & 241.01 & $239.56-242.48$ \\
\hline Rutin & 244.76 & $242.50-247.02$ \\
\hline $\begin{array}{l}\text { Quercetin-3-O- } \beta- \\
\text { glucuronide }(1)\end{array}$ & 74.99 & $73.45-76.53$ \\
\hline
\end{tabular}

$I C_{50}$ values of collagenase inhibition at $\mu \mathrm{M}$ concentrations. Values are the mean of four independent experiments. Doxycycline was used as a positive control

To ensure that no other compounds were involved in the activity, all fractions obtained during purification of the targeted compound were submitted to an in vitro collagenase inhibition test.

This procedure led to the isolation of quercetin-3-O- $\beta$-glucuronide as the active compound, which was identified by $1 \mathrm{D}$ and $2 \mathrm{D}$ NMR, HRMS, and by comparison with literature data [31]. Evidence of the glucuronic acid in the structure was provided by the $\mathrm{HMBC}$ correlation between the signal of the proton at $\delta 3.58$ $\left(\mathrm{H}-4^{\prime \prime}\right)$ in the sugar moiety and the signal of the carbonyl carbon $\left(C-6^{\prime \prime}\right)$ at $\delta$ 173.2. The HRESIMS analysis further confirmed the structure, revealing an $[\mathrm{M}-\mathrm{H}]^{-}$ion $\mathrm{m} / \mathrm{z}$ at 477.0851 in the negative mode (calcd. $\mathrm{C}_{21} \mathrm{H}_{17} \mathrm{O}_{13} 477.0675$ ), confirming the molecular formula of the active compound as $\mathrm{C}_{21} \mathrm{H}_{16} \mathrm{O}_{13}$.

The isolated quercetin-3-O- $\beta$-glucuronide was tested for collagenase inhibitory activity and compared to two standards of other flavonoid glycosides (quercitrin and rutin) and the positive control doxycycline, the only drug approved by the Federal Drug Administration as a collagenase inhibitor [32]. The results ( $\triangleright$ Table 1 ) showed that quercetin-3-O- $\beta$-glucuronide was more potent $\left(\mathrm{IC}_{50}\right.$ of $74.99 \mu \mathrm{M})$ than the positive control doxycycline $\left(\mathrm{IC}_{50}\right.$ of $253.52 \mu \mathrm{M})$ as well as quercitrin and rutin, which expressed $I_{50}$ values similar to the positive control. These results suggest the importance of the presence of the carboxylic acid group $(-\mathrm{COOH})$ in position $6^{\prime \prime}$ of the sugar moiety of this flavonoid for the inhibition of collagenase enzymes.

Flavonoids are a class of natural compounds that are promising as collagenase inhibitors, and this is the first reported evidence of anti-collagenase activity of quercetin-3-O- $\beta$-glucuronide. It is likely that flavonoid metal chelating properties [33] can interfere with both the enzyme active site, which contains $\mathrm{Zn}(\mathrm{II})$, and the environmental $\mathrm{Ca}$ (II) site, which is essential for collagenase and many other MMP catalysis.

In conclusion, metabolomics analysis coupled with multivariate data treatment proved to be an effective approach to identify some common phytochemical features able to confer collagenase inhibitory activity to plant extracts. Particularly, it was possible to establish an apparent correlation between the presence of tanninrelated compounds in several medicinal plants and their anti-collagenase activity.

The invalidation of in vitro bioassays due to the interference of tannins has been reported for some enzymes, such as $\alpha$-glycosi- dase and HIV-1 reverse transcriptase [34,35] as well as for some receptors [36]. However, it is a mistake to generalize this concept, considering that tannins always interfere with all in vitro assays involving proteins. In fact, tannin-protein interactions are not universal but rather depend on specific features of the tannin (size and structure) and the protein (size and amino acid composition) apart from the environment of the reaction such as $\mathrm{pH}$, temperature, solvent, ionic strength, and reaction time. However, according to the results obtained in this study, in the case of the collagenase inhibitory assay, tannins can likely be false inhibitors, and it is recommended to remove them when performing in vitro collagenase inhibitor assays.

The importance of aromatic compounds other than tannins, which were also highlighted by the OPLS model, was further confirmed by the bioassay-guided procedure carried out on A. vulgaris, which yielded a flavonoid, quercetin-3-O- $\beta$-glucuronide, as the active principle. This compound showed a higher potency compared to other flavonoids, as well as to positive control. In the first screening of the crude extracts, $A$. vulgaris was considered to be a medium activity anti-collagenase plant among those tested, but after the tannin-removal procedure, it became the most active. This plant is used topically in Mediterranean traditional medicine for its anti-inflammatory properties and to improve the healing of wounds and burns. The obtained results support its traditional uses, encouraging further investigation into its pharmacological properties on extracellular matrix remodeling.

\section{Materials and Methods}

\section{Plant material}

Forty-nine samples from plants used in different traditional medicine systems were analyzed in this study. Dried and powdered Indian plants (used in the Ayurveda tradition) were kindly supplied by Maharishi Ayurveda Product Italy. They were collected in Ram Bagh (Rajasthan, India) and authenticated by Dr. M. R. Uniyal, Maharishi Ayurveda Product Ltd., Noida, India. The Mediterranean plants were kindly supplied by Biokyma S. r.I and were identified by Dr. Franco Maria Bini. Voucher specimens of the crude drugs of Indian and Mediterranean plants were deposited in the Department of Pharmacy and Biotechnology, University of Bologna.

The African plants were collected in six villages of Baskouré and Songretenga communes (Burkina Faso) and identified by Prof. Joseph Issaka Boussim. Voucher specimens were deposited in the herbarium of the Botanical Laboratory of the University of Ouagadougou. Details and voucher specimens of the aforementioned plants are shown in Table 1S, Supporting Information.

\section{Extraction for the biological activity test}

Samples of $50 \mathrm{mg}$ of dried and powdered plant material were extracted with $1 \mathrm{~mL}$ of $\mathrm{MeOH} / \mathrm{H}_{2} \mathrm{O}(1: 1)$ and sonicated for $30 \mathrm{~min}$. After this procedure, the samples were centrifuged for $20 \mathrm{~min}$ $(1700 \times g)$, then the supernatants were separated from the pellet and dried to yield the crude extracts. 


\section{Tannin removal}

The raw extracts were solubilized in the minimum amount of $\mathrm{MeOH} / \mathrm{H}_{2} \mathrm{O}(1: 1)$ and loaded on a polyamide column $(10 \times 1 \mathrm{~cm})$ in a ratio of $0.5 \mathrm{~g}$ of sorbent for $100 \mathrm{mg}$ of extract. The column was subsequently eluted with $6 \mathrm{~mL}$ of $\mathrm{EtOH}$ and was taken to dryness at a low temperature $\left(<40^{\circ} \mathrm{C}\right)$ under reduced pressure yielding the tannin-free fractions.

\section{Sample preparation for ${ }^{1} \mathrm{H}$ NMR metabolomic analysis}

Briefly, $0.05 \mathrm{~g}$ of dried and powdered plant material was extracted using $1 \mathrm{~mL}$ of a mixture $(1: 1)$ of phosphate buffer $(90 \mathrm{mM}$, $\mathrm{pH}$ 6.0; Fluka Chemika) in $\mathrm{D}_{2} \mathrm{O}$ containing $0.1 \%$ trimethylsilylpropionic-2,2,3,3- $d_{4}$ acid sodium salt (TMSP) and $\mathrm{CD}_{3} \mathrm{OD}$ by ultrasonication for $30 \mathrm{~min}$. After this procedure, samples were centrifuged for $20 \mathrm{~min}(1700 \times \mathrm{g})$ and $300 \mu \mathrm{L}$ of the extract were transferred into NMR microtubes.

\section{NMR measurement}

${ }^{1} \mathrm{H}$ NMR spectra, J-resolved, ${ }^{1} \mathrm{H}-{ }^{1} \mathrm{H}$ homonuclear, and inverse detected ${ }^{1} \mathrm{H}-{ }^{13} \mathrm{C}$ correlation experiments were recorded at $25^{\circ} \mathrm{C}$ on a Bruker $600 \mathrm{MHz}$ AVANCE II NMR spectrometer $(600.13 \mathrm{MHz}$ operating at the ${ }^{1} \mathrm{H}$ frequency) equipped with a $\mathrm{TCl}$ cryoprobe and $\mathrm{Z}$ gradient system. $\mathrm{CD}_{3} \mathrm{OD}$ was used for internal lock purposes.

\section{LC-MS analysis}

UHPLC-TOF-MS analyses were performed on an UHPLC system (Ultimate 3000, ThermoScientific) coupled to an ESI-Q-TOF mass spectrometer (micrOTOF-QII, Bruker Daltonics) in the negative mode. The chromatographic separation was done using a Kinetex $\mathrm{C}_{18}$ UHPLC $2.6 \mu \mathrm{m}, 150 \times 2.0 \mathrm{~mm}$ column (Phenomenex) at a flow rate of $0.3 \mathrm{~mL} / \mathrm{min}$ and a column temperature of $30^{\circ} \mathrm{C}$. Samples $(3 \mu \mathrm{L})$ were eluted using a gradient of solvent $A\left(\mathrm{H}_{2} \mathrm{O}\right)$ and $B$ $(\mathrm{AcCN})$, both with $0.1 \%$ formic acid $(\mathrm{v} / \mathrm{v})$. The initial percentage of B was $5 \%$, which was linearly increased to $90 \%$ in $19.5 \mathrm{~min}$, followed by a 2-min isocratic period, and then re-equilibrated to the original conditions in 2 min. Nitrogen was used as the drying and nebulizing gas. The gas flow was set at $10.0 \mathrm{~L} / \mathrm{min}$ at $250{ }^{\circ} \mathrm{C}$, and the nebulizer pressure was 2.0 bar. The MS data were acquired over an $\mathrm{m} / \mathrm{z}$ range of $100-1000$. The capillary voltage was $3.5 \mathrm{kV}$. For the internal calibration, a $10-\mathrm{mM}$ solution of sodium formate (Fluka) was infused. Formic acid, $\mathrm{H}_{2} \mathrm{O}$, and $\mathrm{AcCN}$ were of LC-MS grade (Optima, Fisher Scientific).

\section{Multivariate data analysis}

The ${ }^{1} \mathrm{H}$ NMR spectra were automatically reduced to ASCII files. Spectral intensities were reduced to integrated regions of equal width $(\delta 0.04)$ corresponding to the region from $\delta 0.0$ to 10.0 . The regions of $\delta 5-4.5$ and 3.34-3.30 were excluded from the analysis because of the residual signals of $D_{2} \mathrm{O}$ and $C_{3} \mathrm{OD}$, respectively. Bucketing was performed by AMIX software (Bruker) with scaling on total intensity. SIMCA-P+ software (v. 15.0, Umetrics) was used in order to perform the OPLS model for multivariate data analysis.

\section{Collagenase inhibitory assay}

Biological assays were performed using a microplate reader, Victor X3 Perkin-Elmer (Perkin-Elmer). The assay was performed as described by Mandrone et al. [37].

Collagenase (E.C. 3.4.24.3) from Clostridium histolyticum (type IA, ChC; specific activity $11.72 \mathrm{U} / \mathrm{mg}$ ) was purchased from Sigma-Aldrich Co. Twenty mU of enzyme, prepared in Tricine buffer $(0.05 \mathrm{M}, \mathrm{pH} 7.5)$ containing $0.4 \mathrm{M} \mathrm{NaCl}$ and $0.01 \mathrm{M} \mathrm{CaCl}_{2}$, were incubated for 5 min with the extract at a concentration of $50 \mu \mathrm{g} /$ $\mathrm{mL}$. The synthetic substrate N-(3-[2-Furyl]-acryloyl)-LeuGly-ProAla (FALGPA), prepared in the same buffer solution, was added to start the reaction (final concentration of $0.8 \mathrm{mM}$ ) in a final volume of $125 \mu \mathrm{L}$. Samples stock solutions were prepared using $\mathrm{H}_{2} \mathrm{O} /$ DMSO, with a final concentration of DMSO in the assay of $3 \%$. The change in absorbance was monitored over a time interval of $5 \mathrm{~min}$ at $340 \mathrm{~nm}$ in a microplate reader at a constant temperature of $30^{\circ} \mathrm{C}$. In order to calculate the $\mathrm{IC}_{50}$, linear regression curves, showing sample concentrations (from 5 to $500 \mu \mathrm{M}$ ) on the $\mathrm{x}$-axis and percentage inhibition on the y-axis, were built using Graph Pad Prism 4 software (Fig. 2S, Supporting Information). Doxycycline (purity $\geq 98 \%$; Sigma-Aldrich Co.) was used as a positive control, while the negative control was obtained measuring the reaction of the enzyme and substrate in buffer solution containing DMSO $3 \%$. Results are the mean of four independent experiments.

The percentage of enzymatic inhibitory activity was calculated using the following formula:

$\%$ inhibition $=[1-(\Delta \mathrm{Abs} / \mathrm{min}$ sample $/ \Delta \mathrm{Abs} / \mathrm{min}$ negative control $) \times 100]$

\section{Isolation of quercetin-3-O- $\beta$-glucuronide from Alchemilla vulgaris}

The dried and powdered aerial part of the plant material $(1000 \mathrm{~g})$ was exhaustively extracted using $10 \mathrm{~L}$ of $\mathrm{MeOH} / \mathrm{H}_{2} \mathrm{O}(1: 1, \mathrm{v} / \mathrm{v})$. The crude extract was filtered in a Büchner funnel and dried under reduced pressure in a rotary evaporator, yielding $100 \mathrm{~g}$ of dry extract. The extract was suspended in $\mathrm{H}_{2} \mathrm{O}$ and successively partitioned with $n$-hexane, $\mathrm{CHCl}_{3}$, and $n-\mathrm{BuOH}$. A concentration of $0.05 \mathrm{mg} / \mathrm{mL}$ of each fraction was submitted to the bioassay. The $n$-BuOH fraction (13.6 g) was the most active, and was thus further fractionated using an MPLC instrument (Sepacore, Büchi) equipped with a UV detector and fraction collector. The extract was dissolved in a proper amount of $\mathrm{MeOH} / \mathrm{H}_{2} \mathrm{O}$ and loaded onto an $\mathrm{HP}-20$ resin column $(3 \times 40 \mathrm{~cm}$; Sigma-Aldrich $)$ and eluted with a gradient of $\mathrm{H}_{2} \mathrm{O}$ (solvent $\mathrm{A}$ ) and $\mathrm{EtOH}$ (solvent $\mathrm{B}$ ) with an initial content of $0 \% \mathrm{~B}$ ( $4 \mathrm{~min}$ ), followed by linear increases to 25 (4 min), 50 (4 min), 75 ( $4 \mathrm{~min})$, and $100 \%$ (4 min). The flow rate was $50 \mathrm{~mL} / \mathrm{min}$, and subfractions of $50 \mathrm{~mL}$ were collected and combined into 11 subfractions (A1-A11).

Subfraction A8 $(0.93 \mathrm{~g})$ showed the highest activity value in the collagenase inhibitory assay and was further fractionated by MPLC using a column of $80 \mathrm{~g}$ of silica gel at a flow rate of $20 \mathrm{~mL} /$ min and was eluted with a gradient of $\mathrm{CHCl}_{3}$ (solvent $\mathrm{A}$ ) and acetic acid $2 \%$ in $\mathrm{MeOH}(\mathrm{v} / \mathrm{v}$ ) (solvent $\mathrm{B}$ ). Initial conditions were $10 \% \mathrm{~B}$ for 15 min followed by a linear increase to $30 \%$ B in 5 min, 30\% B for $20 \mathrm{~min}$, a linear increase $50 \%$ B in $5 \mathrm{~min}$, and finally $50 \%$ B for 
10 min. Subfractions of $10 \mathrm{~mL}$ were collected and grouped into 4 subfractions (B1-B4).

The most active fraction, B4, was further separated by MPLC with a $C_{18}$ column $(4 \mathrm{~g}$ ) at a flow rate of $10 \mathrm{~mL} / \mathrm{min}$, collecting $10 \mathrm{~mL}$ fractions. The fraction was eluted with a gradient of $\mathrm{H}_{2} \mathrm{O}$ (solvent A) and $\mathrm{MeOH}$ (solvent $\mathrm{B}$ ), both with $1 \%$ formic acid. Initial conditions were $10 \%$ B for 10 min followed by a linear increase of $10-20 \%$ B in $1 \mathrm{~min}$, isocratic elution with $20 \%$ B for 20 min, increase to $30 \% \mathrm{~B}$ in $1 \mathrm{~min}, 30 \% \mathrm{~B}$ for $10 \mathrm{~min}$, increase of $30-50 \% \mathrm{~B}$ in $1 \mathrm{~min}, 50 \% \mathrm{~B}$ for $10 \mathrm{~min}$, increase of $50-70 \% \mathrm{~B}$ in $1 \mathrm{~min}$, and finally $70 \%$ B for $5 \mathrm{~min}$. This resulted in seven subfractions (D1 to D7).

Fraction D4 (26.55 mg) was further purified on a Sephadex LH20, $2 \mathrm{~cm} \times 180 \mathrm{~cm}$ column (GE Healthcare) and eluted with $\mathrm{MeOH}$. This yielded quercetin-3-O- $\beta$-glucuronide. All fractions obtained throughout fractionation and purification were analyzed using both ${ }^{1} \mathrm{H}$ NMR and TLC (silica gel F254; Merck) with a mobile phase composed of EtOAc/AcOH/HCOOH/ $\mathrm{H}_{2} \mathrm{O}(100: 11: 11: 27)$ and visualized both at UV-Vis 254 and $336 \mathrm{~nm}$ and chemical derivatization with anisaldehyde spray followed by heating.

Quercetin-3-O- $\beta$-glucuronide: yellow powder $(\mathrm{MeOH}) ;{ }^{1} \mathrm{H}$ NMR $\left(\mathrm{CD}_{3} \mathrm{OD}, 600 \mathrm{MHz}\right) \delta 7.73\left(1 \mathrm{H}, \mathrm{d}, J=2.0 \mathrm{~Hz}, \mathrm{H}-2^{\prime}\right), 7.59(1 \mathrm{H}, \mathrm{dd}$, $\left.J=8.5,2.2 \mathrm{~Hz}, \mathrm{H}-6^{\prime}\right), 6.85\left(1 \mathrm{H}, \mathrm{d}, J=8.4 \mathrm{~Hz}, \mathrm{H}-5^{\prime}\right), 6.39(1 \mathrm{H}, \mathrm{d}$, $J=2.1 \mathrm{~Hz}, \mathrm{H}-8), 6.20(1 \mathrm{H}, \mathrm{d}, J=2.1 \mathrm{~Hz}, \mathrm{H}-6), 5.37(1 \mathrm{H}, \mathrm{d}$, $\left.J=7.5 \mathrm{~Hz}, \mathrm{H}-1^{\prime \prime}\right), 3.68\left(1 \mathrm{H}, \mathrm{t}, J=9.9 \mathrm{~Hz}, \mathrm{H}-5^{\prime \prime}\right), 3.57(1 \mathrm{H}, \mathrm{t}$, $\left.J=9.3 \mathrm{~Hz}, \mathrm{H}-4^{\prime \prime}\right), 3.47\left(1 \mathrm{H}, \mathrm{t}, J=8.8 \mathrm{~Hz}, \mathrm{H}-2^{\prime \prime}\right), 3.47(1 \mathrm{H}, \mathrm{t}$, $\left.J=8.7 \mathrm{~Hz}, \mathrm{H}-3^{\prime \prime}\right) ;{ }^{13} \mathrm{C} \mathrm{NMR}\left(\mathrm{CD}_{3} \mathrm{OD}, 150 \mathrm{MHz}\right) \delta 173.3(\mathrm{COOH}, \mathrm{C}-$ 6' '), 166.0 (COH, C-7), 162.7 (COH, C-5), 159.0 (C, C-2), 158.3 (C, C-9), 149.9 (COH, C-4'), 145.9 (COH, C-3'), 135.5 (COR, C-3), 123.0 (C, C-6'), 117.0 (C, C-2'), 115.7 (C, C-5'), 105.5 (C, C-10), $103.8\left(\mathrm{COH}, \mathrm{C}-1^{\prime \prime}\right), 99.5$ (C, C-6), 94.4 (C, C-8), $77.6(\mathrm{COH}, \mathrm{C}-$ 3'), 77.1 (CCOOH, C-5'), $75.3\left(\mathrm{COH}, \mathrm{C}-2^{\prime \prime}\right), 72.5\left(\mathrm{COH}, \mathrm{C}-4^{\prime \prime}\right)$; ESIMS (negative ion mode) $\mathrm{m} / \mathrm{z} 477.1[\mathrm{M}-\mathrm{H}]^{-}$; HRESIMS m/z $477.0851[\mathrm{M}-\mathrm{H}]^{-}$(calcd. for $\mathrm{C}_{21} \mathrm{H}_{17} \mathrm{O}_{13}$ 477.0675).

\section{Supporting information}

A table showing the data of the plant material (traditional medicine source, scientific name, used part, percentage of anti-collagenase activity) and the ${ }^{1} \mathrm{H}$ NMR spectra of $H$. indicus extract before and after the polyamide column are available as Supporting Information.

\section{Acknowledgements}

The authors appreciate all the valuable comments and revisions of Dr. Erica Wilson. Dr. Luca Cornioli, Dr. Paolo Scartezzini, and Dr. Pascal Nadembega are appreciated for kindly providing the plant materials employed in this study. Dr. A. Coqueiro thanks Ciências sem Fronteiras, CAPES Foundation, Ministry of Education of Brazil, for the scholarship support.

\section{Conflict of Interest}

The authors declare no conflict of interest.

\section{References}

[1] Cragg GM, Newman DJ. Natural products: a continuing source of novel drug leads. Biochim Biophys Acta 2013; 1830: 3670-3695

[2] Cragg GM, Grothaus PG, Newman DJ. Impact of natural products on developing new anti-cancer agents. Chem Rev 2009; 109: 3012-3043

[3] Pauli GF, Chen SN, Friesen JB, McAlpine JB, Jaki BU. Analysis and purification of bioactive natural products: the AnaPurNa study. J Nat Prod 2012; 75: 1243-1255

[4] Butler MS. The role of natural product chemistry in drug discovery. J Nat Prod 2004; 67: 2141-2153

[5] Yuliana ND, Khatib A, Choi YH, Verpoorte R. Metabolomics for bioactivity assessment of natural products. Phytother Res 2011; 25: 157-169

[6] Wolfender JL, Marti G, Thomas A, Bertrand S. Current approaches and challenges for the metabolite profiling of complex natural extracts. J Chromatogr A 2015; 1382: 136-164

[7] Inui T, Wang Y, Pro SM, Franzblau SG, Pauli GF. Unbiased evaluation of bioactive secondary metabolites in complex matrices. Fitoterapia 2012; 83: $1218-1225$

[8] Yuliana ND, Khatib A, Verpoorte R, Choi YH. Comprehensive extraction method integrated with NMR metabolomics: a new bioactivity screening method for plants, adenosine A1 receptor binding compounds in Orthosiphon stamineus Benth. Anal Chem 2011; 83: 6902-6906

[9] Cardoso-Taketa AT, Pereda-Miranda R, Choi YH, Verpoorte R, Villarreal ML. Metabolic profiling of the Mexican anxiolytic and sedative plant Galphimia glauca using nuclear magnetic resonance spectroscopy and multivariate data analysis. Planta Med 2008; 74: 1295-1301

[10] Ali K, Iqbal M, Yuliana ND, Lee Y], Park S, Han S, Lee JW, Lee HS, Verpoorte R, Choi YH. Identification of bioactive metabolites against adenosine A1 receptor using NMR-based metabolomics. Metabolomics 2013; 9: 778-785

[11] Tawfike AF, Viegelmann C, Edrada-Ebel R. Metabolomics and dereplication strategies in natural products. Methods Mol Biol 2013; 1055: 227244

[12] Hubert J, Nuzillard JM, Renault JH. Dereplication strategies in natural product research: How many tools and methodologies behind the same concept? Phytochem Rev 2017; 16: 55-95

[13] Katiyar C, Gupta A, Kanjilal S, Katiyar S. Drug discovery from plant sources: An integrated approach. Ayu 2012; 33: 10-19

[14] Khare CP. Indian herbal Remedies: rational Western Therapy, Ayurvedic, and other traditional Usage, Botany. New Delhi: Springer Science \& Business Media; 2004

[15] Nadembega P, Boussim JI, Nikiema JB, Poli F, Antognoni F. Medicinal plants in Baskoure, Kourittenga province, Burkina Faso: an ethnobotanical study. J Ethnopharmacol 2011; 133: 378-395

[16] Guarrera PM. Usi e Tradizioni della Flora italiana. Medicina Popolare ed Etnobotanica. Roma: Aracne editore; 2006

[17] Saric S, Clark AK, Sivamani RK, Lio PA, Lev-Tov HA. The role of polyphenols in Rosacea treatment: a systematic review. J Altern Complement Med 2017; 23: 920-929

[18] Ezeja MI, Anaga AO. Anti-ulcerogenic activity of the methanol root bark extract of Cochlospermum planchonii (Hook f). Afr J Tradit Complement Altern Med 2013; 10: 394-400

[19] Elliott S, Cawston T. The clinical potential of matrix metalloproteinase inhibitors in the rheumatic disorders. Drug Aging 2001; 18: 87-99

[20] Schultz G, Mozingo D, Romanelli M, Claxton K. Wound healing and TIME; new concepts and scientific applications. Wound Repair Regen 2005; 13 : $\mathrm{S} 1-\mathrm{S} 11$

[21] Chambers T], Darby JA, Fuller K. Mammalian collagenase predisposes bone surfaces to osteoclastic resorption. Cell Tissue Res 1985; 241: $671-675$ 
[22] Nissinen L, Kähäri VM. Matrix metalloproteinases in inflammation. Biochim Biophys Acta 2014; 1840: 2571-2580

[23] Thring TS, Hili P, Naughton DP. Anti-collagenase, anti-elastase and antioxidant activities of extracts from 21 plants. BMC Complement Altern Med 2009; 9: 27

[24] Chatatikun M, Chiabchalard A. Thai plants with high antioxidant levels, free radical scavenging activity, anti-tyrosinase and anti-collagenase activity. BMC Complement Altern Med 2017; 17: 487

[25] Ghimeray AK, Jung US, Lee HY, Kim YH, Ryu EK, Chang MS. In vitro antioxidant, collagenase inhibition, and in vivo anti-wrinkle effects of combined formulation containing Punica granatum, Ginkgo biloba, Ficus carica, and Morus alba fruits extract. Clin Cosmet Investig Dermatol 2015; 8 : 389-396

[26] Crascì L, Lauro MR, Puglisi G, Panico A. Natural antioxidant polyphenols on inflammation management: Anti-glycation activity vs. metalloproteinases inhibition. Crit Rev Food Sci Nutr 2018; 58: 893-904

[27] Burlando B, Pastorino G, Salis A, Damonte G, Clericuzio M, Cornara L. The bioactivity of Hedysarum coronarium extracts on skin enzymes and cells correlates with phenolic content. Pharm Biol 2017; 55: 1984-1991

[28] Tanimura S, Kadomoto R, Tanaka T, Zhang Y], Kouno I, Kohno M. Suppression of tumor cell invasiveness by hydrolyzable tannins (plant polyphenols) via the inhibition of matrix metalloproteinase-2/-9 activity. Biochem Biophys Res Commun 2005; 330: 1306-1313

[29] Krishnamoorthy G, Sehgal PK, Mandal AB, Sadulla S. Studies on collagentannic acid-collagenase ternary system: Inhibition of collagenase against collagenolytic degradation of extracellular matrix component of collagen. J Enzyme Inhib Med Chem 2012; 27: 451-457

[30] Hagerman AE, Butler LG. Protein precipitation method for the quantitative determination of tannins. J Agric Food Chem 1978; 26: 809-812

[31] Bouktaib M, Atmani A, Rolando C. Regio- and stereoselective synthesis of the major metabolite of quercetin, quercetin-3-O- $\beta$-D-glucuronide. Tetrahedron Lett 2002; 43: 6263-6266

[32] Wynn RL. Latest FDA approvals for dentistry. Gen Denti 1999; 47: 19

[33] Mira L, Fernandez MT, Santos M, Rocha R, Florêncio MH, Jennings KR. Interactions of flavonoids with iron and copper ions: a mechanism for their antioxidant activity. Free Radic Res 2002; 36: 1199-1208

[34] Li DQ, Zhao J, Xie J, Li SP. A novel sample preparation and on-line HPLC-DAD-MS/MS-BCD analysis for rapid screening and characterization of specific enzyme inhibitors in herbal extracts: case study of $\alpha$-glucosidase. J Pharm Biomed Anal 2014; 88: 130-135

[35] Tan GT, Pezzuto JM, Kinghorn AD, Hughes SH. Evaluation of natural products as inhibitors of human immunodeficiency virus type 1 (HIV-1) reverse transcriptase. J Nat Prod 1991; 54: 143-154

[36] Zhu M, Phillipson JD, Greengrass PM, Bowery NE, Cai Y. Plant polyphenols: biologically active compounds or non-selective binders to protein? Phytochemistry 1997; 44: 441-447

[37] Mandrone M, Lorenzi B, Venditti A, Guarcini L, Bianco A, Sanna C, Ballero $\mathrm{M}$, Poli F, Antognoni F. Antioxidant and anti-collagenase activity of $\mathrm{Hy}$ pericum hircinum L. Ind Crop Prod 2015; 76: 402-408 